\title{
La neurociencia como medio de suplir vacíos legales: análisis a la prueba del dolor
}

\section{Neuroscience as a means of filling legal gaps: pain test analysis}

DOI: https://doi.org/10.17981/juridcuc.15.1.2019.04

Fecha de Recepción: 22/02/2019 Fecha de Aceptación: 20/06/2019

\author{
Fernando Luna Salas \\ Universidad de Cartagena, Cartagena (Colombia) \\ flunas@unicartagena.edu.co
}

Virgilio Escamilla Arrieta

Universidad de Cartagena, Cartagena (Colombia) virgilioescamilla@hotmail.com

Adriana Corena Simancas

Universidad de Cartagena, Cartagena (Colombia) adrianacore27@gmail.com

Para citar este artículo:

Luna, F., Escamilla, V. y Corena, A. (2019). La neurociencia como medio de suplir vacíos legales: análisis a la prueba del dolor. JURÍDICAS CUC, 15(1). 96-134. DOI: http://dx.doi.org/10.17981/ juridcuc.15.1.2019.04

Resumen

El presente trabajo es de carácter jurídico - reflexivo, y se aborda desde la investigación cualitativa con revisión bibliográfica. Se centra en describir y analizar un vacío legal ignorado por gran parte de la comunidad científica, pues, no lo han considerado como tal, y para efectos de este artículo, se denominará la prueba del dolor. Así mismo, se plantea como propuesta para solucionarlo, las herramientas y técnicas de la neurociencia, que permiten la cuantificación del dolor y su respectiva valoración económica. De tal manera, se proyecta la idea de una relación ineludible entre el Derecho y el desarrollo de las ciencias exactas, posibilitando la construcción de nuevos conceptos que en últimas, contribuirán al progreso del Ordenamiento Jurídico.

Palabras claves: Vacío legal; ordenamiento jurídico; prueba; dolor; daño; neurociencia
Abstract

This work is of a legal - reflexive nature, and is approached from qualitative research with bibliographic review. It focuses on describing and analysing a legal vacuum ignored by a large part of the scientific community, since it has not been considered as such, and for the purposes of this article, it will be called the pain test. Likewise, the tools and techniques of neuroscience, which allow the quantification of pain and its respective economic valuation, are proposed as a solution. In this way, the idea of an unavoidable relationship between Law and the development of exact sciences is projected, making possible the construction of new concepts that will ultimately contribute to the progress of the Juridical Order

Keywords: Legal vacuum; legal order; evidence; pain; injury; neuroscience 


\section{INTRODUCCIÓN}

Para la resolución de problemas prácticos, en cualquier campo de la vida, es utilizado el conocimiento científico como instrumento que "conquista lo imposible", lo cual plantea una pregunta: ¿existen imposibles en el campo del Derecho? En principio, no, porque tenemos la ciencia, haciendo referencia a la formal, exacta o fáctica; sin embargo, cuando se alejan la una de la otra, y se deja de lado la conexión inexorable que la ciencia jurídica tiene con el desarrollo de las ciencias exactas, es difícil llegar a ese punto de lo posible.

En relación con lo anterior, en el derecho existen los denominados vacíos legales, esto es, la ausencia en el Ordenamiento Jurídico de una norma para regular un caso concreto. "La existencia de lagunas puede deberse a cualquier motivo imputable al legislador (Laguna Subjetiva) o al envejecimiento del Derecho como consecuencia de la evolución Social (Laguna Objetiva)" (Mercado, 2011, p. 78). Sin embargo, el ordenamiento Jurídico como conjunto de normas, leyes, principios, costumbres -como un todo- no da cabida a estos vacíos, los cuales pueden ser eliminados mediante procedimientos; como lo es el mecanismo de la integración jurídica. Entonces, a pesar de los vacíos que pueden surgir en la ley, se logra regular todos los hechos presentes y futuros alcanzando así lo que se conoce como "Plenitud del Ordenamiento Jurídico".

Lo mencionado en el párrafo precedente no es del todo cierto desde un punto de vista personal-. Imaginar un escenario donde exista un vacío legal, el cual siempre ha estado presente y es de conocimiento de todos, y por lo tanto no se puede encuadrar en una laguna de tipo objetivo; ni mucho menos se puede imputar al legislador. Estos son hechos o situaciones que van más allá del ordenamiento jurídico y a ello se suma que no están al alcance de la ciencia, sencillamente no tienen solución. Se aclara que no se hace referencia a situaciones en las que el derecho se 
quedó atrás y no se adaptó al desarrollo de la sociedad; sino, de hechos en los que las ciencias jurídicas no pueden ahondar porque no cuenta con las herramientas necesarias para hacerlo, desencadenando en lagunas.

En este sentido, se debe insistir en el proceso investigativo sobre los denominados vacíos legales, sin desconocer que, al intentar llenarlos, hay que afirmar con López (2000):

No me parece que el derecho, como técnica de discusión social, se concentre en certidumbres (...) La coherencia es, si se quiere, el esfuerzo por entender un sistema que nace entre las tensiones que generan sus múltiples niveles surcados por la polivalencia política, por la complejidad normativa, por la multitud de transplantes y prestamos jurídicos, por la herencia intelectual y material de épocas dispares. En el gran costal del derecho se presentan siempre estas polifonías y no es tarea fácil reducirlas a una sola melodía (y quizá ni siquiera sea lo deseable) (p. 205).

Ahora bien, el problema mayor es cuando en un escenario similar al descrito, sigan persistiendo los mismos vacíos a pesar de que la comunidad científica haya avanzado y posteriormente descubierto la forma de solucionarlo.

De acuerdo con lo expuesto, en este trabajo se ha identificado como vacío legal la prueba del dolor, toda vez que, actualmente en los procesos judiciales no existe un método con precisión para determinar la cuantificación del dolor y en tal medida permita traducirlo en una posible indemnización, situación que es viable de solucionar a través de los avances científicos, como son las técnicas de las neurociencias, las cuales el Derecho ha ignorado. Para esta investigación, se deja claro que "el dolor es un hecho fundamentalmente subjetivo" (Picó, 2013, p. 83). Dado ese carácter netamente subjetivo sería muy difícil demostrar su existencia o el grado en que se percibe, se habla aquí de una cuantificación del dolor y no del daño. Es importante 
preguntarse ¿Por qué cuantificar el dolor? Efectivamente, en los ordenamientos jurídicos de los diferentes Estados existen tasas fijas para indemnizar el daño con ocasión a un hecho dañoso; sin embargo, en ningún momento se tienen en cuenta la intensidad del dolor que percibe la persona quien recibe el daño o sí este realmente existe.

\section{MetodoloGía}

El presente trabajo jurídico-reflexivo constituye un informe de avance de proyecto de investigación, cuyo abordaje se hace desde la investigación cualitativa de tipo documental y analítico. Este, se fundamenta en el análisis documental, por lo cual, las fuentes son de carácter secundario, consistentes principalmente en revisión de normas, jurisprudencia y doctrina, información recolectada y organizada usando matrices de datos; para posteriormente ser analizadas y establecer en función de responder los siguientes interrogantes: lo que se indemniza es el dolor pero lo que se cuantifica es el daño; ¿Debemos asimilar el dolor al daño, o considerar que lo doloroso produce daño? ¿Se hace necesario separarlos, o el dolor en su manifestación, es el propio daño "antijurídico"? ¿Sería más apropiado cuantificar e indemnizar el dolor? Pero si el dolor es subjetivo ¿Cómo cuantificarlo? ¿Cómo plasmar el contenido inmaterial del dolor en exacta cuantía monetaria? O, peor aún, ¿cómo probarlo dentro de un proceso judicial? La ciencia ha intentado buscar diferentes herramientas para demostrar la existencia e intensidad del dolor, así como "recientes avances en neurociencia han permitido, mediante imágenes computarizadas, detectar la región del cerebro activa cuando se aplican estímulos dolorosos (la matriz del dolor), por lo cual con ellas es posible probar la existencia del dolor" (Picó, 2013, p. 90). ¿Es la neurociencia la solución ante este vacío legal? ¿Realmente existe un vacío legal? ¿Debemos simplemente aceptar que el arbitrio judicial es el único método para señalar 
montos en el insondable ámbito de reconocer el dolor como objeto indemnizable?

Por estas razones el trabajo investigativo tiene como finalidad ahondar en el vacío legal, o en la carencia jurisprudencial sobre otras formas que hagan factible "la prueba del dolor", desde un perfil científico-formal, con la pretensión de no seguir con estos vacíos; sino suplirlos, para llegar a una aproximación de plenitud del ordenamiento jurídico, con la anotada dificultad para el alcance absoluto de esa denominada "coherencia" del ordenamiento legal.

\section{La ciencia del cerebro}

Según Llinás (2003):

El cerebro es algo más que el litro y medio de materia grisácea e inerte que ocasionalmente se ve como un encurtido en frascos, sobre algún estante polvoriento de laboratorio. Por el contrario, el cerebro debe considerarse como una entidad viva que genera una actividad eléctrica definida. Tal actividad podría describirse como tormentas eléctricas "autocontroladas" o, si adoptamos el término de uno de los pioneros de la neurociencia, Charles Sherrington, como un "telar encantado" (pp. 22-23).

La Resonancia Magnética Funcional por Imágenes (FMRI), la implantación de electrodos en la superficie celular, la imagen óptica, los chips de sílice contenido en circuitos cerebrales artificiales, entre otros, son una serie de técnicas sofisticadas de investigación que ha desarrollado la neurociencia para analizar la estructura y funcionamiento del cerebro. Ante estos avances científicos y del estudio a profundidad del cerebro, se puede afirmar como esta metodología procura dar respuestas a situaciones que se encontraban inconclusas en diferentes campos del saber científico, como lo es el Derecho. No obstante, antes de llegar a 
ese punto de la investigación es dable dar una explicación sobre la neurociencia, a entendimiento de los estudiosos del derecho, con el fin de comprender su interconexión con el eje central del presente trabajo, la prueba del dolor y su cuantificación monetaria como objeto indemnizable jurídicamente.

Así las cosas, se empezará con la explicación de los conceptos centrales sobre la materia. La neurociencia es la ciencia que se ocupa de estudiar la organización funcional del sistema nervioso central, es decir, del cerebro, a su vez, este sistema está compuesto por el cerebro, la médula espinal y los nervios periféricos. El cerebro se compone del tronco, del encéfalo y de los hemisferios cerebrales. Así mismo, de la corteza cerebral, la cual es fundamental para acciones voluntarias como el lenguaje, el habla y otras funciones superiores como el pensamiento y la memoria.

Sobre las neurociencias, expresa Reyes, Hernández, Chumaceiro y Cadrazco (2016):

Neurociencias se entiende como un conjunto de disciplinas que estudian múltiples dimensiones, abarcando no solo las funciones cerebrales, las estructuras de esta, sino también el desarrollo del sistema nervioso, incluyendo lo patológico, lo farmacológico, la respuesta bioquímica dentro del sistema nervioso central, lo cognitivo y conductual, e incluso la psiquis de cada individuo y como esta repercute no solo en su vida personal sino en su entorno social (p. 59).

De acuerdo a Arteaga (2018) la neurociencia utiliza:

Datos de diversos orígenes, subrayando tanto los puntos de vista morfológicos y fisiológicos como los de la bioquímica, la genética y la biología molecular, así como los resultados de las múltiples técnicas de exploración funcional de la actividad cerebral, desde la electroencefalografía hasta las llamadas técnicas por la imagen (p. 194). 
Así mimo, Cárdenas (2017) considera que:

El extraordinario desarrollo de la neurociencia está llevando a una nueva revolución científica, cambiando una serie de paradigmas. Gracias a ella, se puede entender cada vez más las bases neurológicas de nuestra conciencia y de la razón, la determinación de nuestras conductas y de nuestro yo, las bases de la moralidad, el proceso del pensamiento y de toma de decisiones, el funcionamiento del sistema nervioso, el enfrentamiento de trastornos como el autismo, el Alzheimer o la esquizofrenia, etc. (p. 83).

Es importante anotar que la comunidad científica ha concordado en afirmar que:

Todavía queda mucho por descubrir y aprender y, fundamentalmente en aspectos tan importantes como la conciencia; por lo que el estudio de la corteza cerebral y las funciones en las que está implicada es una de los campos de investigación más activo y excitante dentro de las neurociencias (Asociación Británica de Neurociencias BNA, 2003, p. 5).

\section{Neurociencia del dolor}

En un escenario, cinco voluntarios son sometidos a sumergir sus manos por el mismo periodo de tiempo en un recipiente que contiene agua extremadamente fría. Efectivamente, los cinco sujetos sienten dolor, pero no en la misma intensidad - grado de dolor-, lo cual obedece a la teoría de que el dolor es una percepción, esto implica que tiene una condición subjetiva. Entonces, indudablemente el dolor existe pero se experimenta de manera distinta a su posible realidad; por lo cual es algo que no es sencillo de explicar y mucho menos entender. 
La neurociencia explica cómo es percibido el dolor en el cuerpo de la siguiente manera:

Múltiples variedades de receptores, distribuidos por todo nuestro cuerpo, están sintonizados con diferentes aspectos del mundo somatosensorial (tacto, temperatura, posición del cuerpo), mientras que otros se encargan de percibir el dolor. El poder de discriminación de estos receptores varía en función de la zona del cuerpo, siendo extremadamente sensibles, entre otros, en las yemas de los dedos. La exploración activa es también muy importante ya que interacciona directamente con el sistema motor (BNA, 2003, p. 13).

El dolor nos informa y nos advierte del daño causado a nuestro cuerpo. Tiene un gran impacto emocional y está sujeto a un gran control por parte del cuerpo y del cerebro.

En consecuencia es razonable que las teorías de responsabilidad del Derecho hagan referencia a la indemnización del sujeto por un daño causado con el fin de revertirlo, pero a fondo, se podría decir que en realidad lo que se quiere no es revertir el daño porque esto es fácticamente casi imposible, sino pagar al sujeto por el dolor causado, que es el evolucionado método jurídico, patrimonial y económico para solucionar el conflicto cuando un sujeto de derecho sufre un daño imputable a otro. En consecuencia, lo adecuado en Derecho sería poder demostrar científicamente el dolor, probar a través de algunas técnicas neurocientíficas, la real intensidad del dolor, no mediante la simple y desvirtuable presunción humana, para que surja un daño cierto y medible en símbolos monetarios, o sea, indemnizable jurídicamente.

Continuando con la explicación, estos estudios han revelado que el dolor no es un sentido adicional a la piel, el dolor está íntimamente asociado al sistema nervioso, es así como lo explica la BNA (2003): 
Constituye en realidad un sistema con funciones y organización anatómica totalmente diferentes. Su mayor característica es que es un sentido que aporta sensaciones desagradables que varía dependiendo de la persona y que, sorprendentemente, sus receptores proveen una información limitada sobre la naturaleza del estímulo (p. 14).

Sin embargo, no hay que dejar de lado otros factores que pueden afectar la percepción del dolor. Para esto hay que distinguir entre el sistema para procesar las emociones y aquel sistema del cerebro dedicado a procesar las sensaciones dolorosas. Cuando hay emociones opuestas a las negativas, esto es, tranquilidad, serenidad, empatía y seguridad, pueden hacer que un dolor se sienta menos (Rocha, 2013). Esta teoría se puede fundamentar en un suceso donde un hombre en plena guerra le fue amputado el brazo y pese a esas circunstancias, que para muchos podría parecer dolorosa, continúo socorriendo a sus demás compañeros, él manifiesta que no sintió dolor. Otro ejemplo se da en el mismo escenario de los recipientes de agua extremadamente fría, donde se utilizaron ciertos métodos de distracción con cincos sujetos diferentes, arrojando como resultado para aquellos que fueron sometidos a esta variante -la distracción- lograron tener una mayor resistencia al dolor.

Así pues, la neurociencia tiene por objeto de estudio la comprensión del sistema nervioso, que se podría explicar de forma metafísica como el estudio del sistema mediante el cual funciona la mente humana, científicamente abordado. Así mismo, es claro que las neuronas actúan en función del entorno en el cual interactúa el sujeto.

\section{Neurociencia y derecho}

Varios estudiosos del derecho han analizado los quehaceres jurídicos desde el campo de las neurociencias, obteniendo un mundo de posibilidades. Un ejemplo de ello es lo referente a la 
autonomía de la voluntad, pilar y principio básico jurídico, dado que los estudios realizados por una corriente de neurocientificos apuntan a la no existencia del libre albedrío, el cual tiene como base la autonomía de la voluntad, el cual a su vez reformaría la forma de pensar el derecho penal y el civil. Así mismo, se desarrollan temas como la capacidad, área de la verdad y falsedad, lo que podría estar relacionado con la veracidad de las declaraciones de los testigos, e incluso se ha llegado a hablar de una neurofilosofía y de una neuroética.

El año 2004 marcó un punto de partida importante para la vinculación de la neurociencia y el derecho con la aparición del texto Neuroscience and the Law Brain, Mind, and the Scales of Justice ${ }^{1}$, libro que quizá dio lugar a una aproximación de lo que podría ser el neuroderecho en el common law, este es el momento preciso para resaltar como el sistema jurídico anglosajón lleva ventajas al civil law; que aún se muestra escéptico frente al tema, a lo mejor por temor de caminar por un plano poco explorado.

Para comprender la interacción entre ambas ciencias se entenderá que el cerebro y en general el sistema nervioso central origina y condiciona la conducta humana, la cual es objeto de estudio y a su vez regulada por los sistemas jurídicos. Antes del desarrollo de esta ciencia era impensable, por ejemplo, cuestionar con fundamentos - desde una perspectiva científica y no filosófica- la idea del libre albedrío, asunto que ahora es bastante discutido e incluso ha llegado a replantear y debatir por algunos juristas las tan cimentadas teorías del derecho penal y en otras disciplinas del derecho.

Haciendo un paréntesis, existen estudiosos del Derecho que hablan del fin de la noción de responsabilidad, porque se ha demostrado la inexistencia de la llamada "voluntad", por tanto,

\footnotetext{
1 En este libro se plasma de forma resumida las deliberaciones que se llevaron a cabo en una reunión de 26 neurocientificos, juristas, abogados y jueces para resolver los problemas relacionados con los descubrimientos en la neurociencia y como estos pueden influir en los procedimientos legales, penales y civiles. Es así como las discusiones sobre este tema han ido en aumento.
} 
también sería el final del Derecho Penal, inclusive el Derecho en general (Taruffo, 2013). Estos son postulados de los nominados "neurofilosofos". Este trabajo se aparta de aquellos presupuestos y más aún de una reestructuración de este tipo para el derecho.

Continuando, es por ello que estos descubrimientos y otros futuros por la neurociencia deberían modificar las instituciones jurídicas que se conservan más por la tradición que por cimientos científicos desarrollados a cabalidad.

Son varios los campos en donde el derecho necesita de la neurociencia, temas cruciales como la determinación de la capacidad, y de las modalidades de incapacidad, ser o no imputable, la objetividad e imparcialidad del juez, la voluntad, ser jurídicamente responsables, la veracidad de un testigo, determinar si hubo error como vicio del consentimiento, entre otros, no podrían ser tratado por el derecho sin una explicación desde la neurociencia que explore cómo funcionan estos aspectos en el cerebro y por tanto en la conducta, se reitera, todo ello implica una transformación de la cultura jurídica, ante la oferta científica neuronal, que puede regular sistemas incluso deferentes al complejo análisis de la conducta culpable, como los que han surgido en objetiva responsabilidad, desde la perspectiva económica - financiera, desplazando como inocuas las imputaciones por culpa probada.

En el afán de interconectar estas ciencias, se fundó el Instituto de Neurociencias y Derecho (INeDe) ${ }^{2}$ con una visión canalizadora y consensuada entre juristas y neurocientificos en la medida en que analizan el modo y el ámbito en que los estudios sobre el funcionamiento del sistema nervioso pueden ser utilizados en el sistema legal, válida y eficazmente.

A este punto de la investigación se hace más difícil negar el vínculo y grados de interacción que existe entre neurociencia y

${ }^{2}$ El cual propone promover la investigación científica para examinar las posibles interacciones bidireccionales entre el mundo del derecho de los recientes hallazgos en el estudio del cerebro, sin perder de vista sus limitaciones. 
Derecho. Puesto que esta discusión es interdisciplinaria y trasciende fronteras. Es así como el debate queda planteado y no puede ser ignorado por la comunidad jurista colombiana.

Aplicación de la Neurociencia a casos concretos dentro del ordenamiento jurídico

Frente a las neurociencia y sus aplicaciones, Molina (2013) afirma "que es una de las revoluciones científicas más grandes de los últimos tiempos" (p. 43). El profesor de Derecho Procesal explica como esta ciencia involucra un importante paso en la historia de la humanidad, al llevar consigo consecuencias sociales verdaderamente significativas por tratar de explorar la mentalidad humana a grandes rasgos y aplicarlo en la esfera práctica, de tal modo que intente resolver problemas que hasta el momento han permanecidos sin solución alguna.

La jurisprudencia - dinámica- suele ir un paso más conforme al desarrollo de la realidad social en comparación con la ley -estática- es por ello que esta parte del trabajo se dedica a analizar casos en donde se ha hecho uso de la neurociencia en el área judicial.

En primer lugar se hará referencia a la defensa Twinkie. En 1978 un sujeto llamado Dan White, se dirigió al despacho del alcalde George Moscone y le pidió que le restituyera en su empleo, a lo cual el alcalde se negó. White le mató de un disparo y se dirigió donde el supervisor Harvery Milk, a quien también disparó, ocasionándole la muerte. La defensa de este caso sostiene que no hubo lugar a la premeditación, ya que White consumía reiteradamente y de forma excesiva comida muy azucarada, lo cual derivó en estragos de la química del cerebro, ocasionándole capacidades mentales disminuidas. White fue condenado a cinco años de prisión por homicidio voluntario sin premeditación (Molina, 2013). Este es un caso que da muestra de los primeros pasos de la neurociencia aplicable al proceso judicial, de una forma carente de demostración científica y bastante incipiente. 
Un segundo evento, es el caso de Brian Dugan, en 1983, al ser acusado de raptar, secuestrar y posteriormente matar a una niña de 10 años llamada Jeanine Nicarico. El presunto homicida fue sometido a varios escáneres de la actividad cerebral mientras realizaba diferentes tareas, entre ellas algunos test que valoraban su capacidad de razonamiento moral, se observó que su cerebro mostraba anomalías similares a las detectadas en otros psicópatas (Molina, 2013). Se enmarca este caso como uno de los primeros donde se utilizaron propiamente herramienta de las neurociencias para sostener una defensa, esto es, el uso de la resonancia magnética funcional utilizada como evidencia para demostrar que el sujeto infractor padecía de una enfermedad mental que le impedía controlar su comportamiento.

Un tercer y último caso que llama bastante la atención, ocurrido en 2003, es el de un hombre de cuarenta años, profesor y padre de familia, que desarrolló un creciente interés en la pornografía infantil llevándolo a acosar a sus alumnos (Molina, 2013). En última instancia fue condenado a prisión, lugar en el cual se le descubrió un tumor cerebral. Después de la extirpación del agente anómalo, deja de lado sus conductas sexuales y es puesto en libertad. Un tiempo después vuelve a presentar las mismas conductas sexuales y se descubre que hay un crecimiento del tumor, lo cual lleva a concluir que si se vuelve a repetir la intervención quirúrgica pueden desaparecer estas conductas. Todo este estudio se debe gracias a las herramientas de las neuroimagenes, las cuales permitieron determinar que su conducta no era de tipo delictual, por tanto no había lugar a la imputación de responsabilidad. A lo mejor sin el desarrollo de esta ciencia o peor aún sin su aplicación en el área del Derecho, este sujeto probablemente hubiera sido condenado por un delito, que en realidad se traducía a una enfermedad del sistema nervioso.

Hasta el momento son casos en primer lugar de la Corte Suprema de Justicia de los Estados Unidos de Norte América y en segundo lugar que se limitan a la esfera del derecho penal. 
Por lo que cabría preguntarse ¿Qué está ocurriendo en la jurisprudencia colombiana frente a casos similares? ¿Están aplicándose las técnicas de la neurociencia? ¿Podrían utilizarse estos mecanismos de la neurociencia, para esclarecer, por ejemplo, lo reconocido por nuestra jurisprudencia sobre defensas al homicida sustentadas en el concepto de "ira e intenso dolor", como estado emocional producido por otras formas de causa externa, admitidas por la psiquiatría forense, que también alteran el comportamiento neuronal, sin depender de la voluntad del agresor? ¿Se podrían utilizar estos métodos científicos para establecer con mayor certeza el estado de demencia en procesos de declaratoria de incapacidad por interdicción ante causas de afectación neurológica? ¿O en procesos declarativos en los que se debate la válidez o la anulación contractual por haberse celebrado el pacto en los denominados "momentos de lucidez", en esa visión científica de nuestro código civil? ¿O, para evidenciar los complicados conceptos de error invencible, fuerza irresistible o "temor reverencial", o el dolo como factor que convence e induce a la otra parte engañada para realizar el acto fraudulento?

En el campo laboral, ¿para determinar la aptitud en las funciones encomendadas y lograr estabilidad en otro empleo? En el comercial, ¿para la idoneidad en la práctica y en el ejercicio mercantil? En administrativo y en la política, ¿para establecer incluso, la idoneidad al acceso de cargos públicos o para demostrar la nulidad del acto por incompetencia física y mental, presentado en análisis científico neurológico? $\mathrm{O}$, en el concreto objetivo de este trabajo, ¿para medir el dolor y denominado daño moral? ¿Para cuantificar el "pretium doloris", el precio del dolor, como daño indemnizable desde su consagración latina romanista y en el marco de polémicas definiciones doctrinarias?

En comparación con otros países de Latinoamérica, Colombia ha hecho avances en esta área de la investigación; sin embargo, no existe regulación frente a esta profesión. Es decir, no se ha implementado en la formación profesional como tal. Así las cosas 
queda muy difícil la explotación de estas herramientas por la jurisprudencia nacional y aún más, llevar a cabo la interconexión entre el Derecho y la neurociencia en Colombia.

Realizando una revisión a la jurisprudencia nacional, se destaca el aporte de las pruebas neurocientificas en el ámbito del Derecho laboral y especialmente en la Seguridad social. Ante todo se enfatiza en la decisión judicial de la Corte Constitucional con fecha del 1 de abril de 2005, mediante la cual negaba las pretensiones del actor, reclamadas a través de acción de tutela. Lo que se destaca de la aludida providencia son los anexos probatorios, entre los cuales se encuentra como prueba el "Informe del Grupo de Neurociencias, que dictamina su dolencia" y los "Informes de evaluación del Instituto Neurológico de Antioquia" (Sentencia T-309, 2005); ello con el propósito de probar la reducción de un $26.85 \%$ de la capacidad laboral del actor, lo que le impide desempeñar su labor normalmente y de conformidad, solicita un reintegro en su lugar de trabajo con reubicación en el mismo.

De otra parte, en sentencia de la Corte Constitucional del 14 de mayo de 2014, mediante la cual se declara exequible el artículo $1^{\circ}$ de la Ley 1638 de 2013, prohibiendo el uso de animales silvestres, nativos o exóticos en circos fijos e itinerantes, en aclaración de voto de los magistrados Nilson Pinilla Pinilla y Jorge Iván Palacio Palacio, sustentando la negativa de inexequibilidad de la norma en mención, basándose en la prueba neurocientífica, en el entendido que los estudios de las neurociencias probaron que los animales son seres vivos, sintientes, con capacidades, niveles de raciocinio y, por tanto, con una serie de intereses por satisfacer (Sentencia C-283, 2014), de allí que se propicie por el reconocimiento y titularidad de ciertos derechos a estos.

Ahora bien, dejando eso de lado y continuado con el objeto de este trabajo reflexivo, cabe advertir, como se ha visto, que la aplicación de la neurociencia se ha desarrollado a grandes pasos respecto del ámbito del Derecho penal, lo cual hace más 
difícil cumplir el objetivo trazado en esta investigación, sin que, como viene anotado, podamos explorar en otras áreas dado el común comportamiento humano en la categoría y como sujeto de derecho. Así cabe aclarar que la siguiente parte del trabajo versará sobre conceptos -que pueden ser o no verdaderos-y no teorías probadas, en su totalidad sobre una realidad física del campo del Derecho.

\section{La prueba del dolor en el proceso judicial}

El derecho procesal como el conjunto de normas que regula los requisitos, desarrollo y los efectos del proceso judicial, debe ser interdisciplinario, donde se analicen tanto los contenidos propios del Derecho, dogmas, instituciones, reglas, normas y principios, así como los contenidos derivados de los estudios sociológicos, económicos, políticos, psicológicos y de la neurociencia, y es que la Ciencia y el Derecho no pueden seguir en caminos separados; todo ello porque la visión del Derecho debe ser amplia e integral, por tratarse de una ciencia que regula el complejo mundo de la realidad social. A este respecto, Molina (2013) propone "abandonar el dogma de una teoría pura del proceso para en cambio asimilar la vertiente de una teoría interdisciplinaria del mismo" (p. 63). Lo cual es una visión totalmente moderna del Derecho procesal.

Lo que se plantea en esta parte del trabajo es la posibilidad de que se pueda dar un uso probatorio a las neurociencias. La utilización de las herramientas que proporciona las Neurociencias no representa ningún problema de admisibilidad dentro del proceso. Taruffo (2013) al respecto explica:

Desde el punto de vista de su posible utilización como prueba en el proceso, se puede decir que no surge el problema principal que afecta a las llamadas pruebas científicas y técnicas forenses de investigación, es decir, la eventualidad de que estén desprovistas de una efectiva válidez científica (p. 15). 
Sin embargo, a pesar de las neurociencias poder suministrar al juez fundamentos cognoscitivos más seguros, objetivos y controlables que permitan determinar de manera más racional la verdad de los hechos, el juez como director del proceso siempre debe hacer un análisis crítico y racional de cada uno de los medios de prueba presentadas, y no caer en el mito de la cientificidad y creer que todo lo que provenga de la ciencia es cierto. Al respecto Luna (2018) explica:

Los jueces, como bien se ha dicho, deben evitar que ingresen pruebas que tengan una baja calidad científica o que el proceso se vea invadido de pseudociencias o ciencias basura. Para ello se hace necesario que existan algunos criterios de selección que debe tener el juez a la hora de valorar la admisibilidad de la prueba científica. La Corte Suprema de Justicia de los Estados Unidos, dentro de un proceso en donde se profirió una providencia mejor conocida como sentencia Daubert, estableció los parámetros que deben ser tenidos en cuenta por el juez a la hora de valorar una prueba científica allegada por un experto. El juez Blackmun, dentro de esa sentencia, planteó cuales son las condiciones mínimas que deben existir para hablar de ciencia en un aspecto procesal, así como también manifestó que no se debe admitir el peritaje si no se cumplen ciertos requisitos epistemológicos (p. 136).

Por otro lado se ha indicado que podría surgir un problema de relevancia con este tipo de prueba. Taruffo (2013) expone:

El problema con el empleo procesal de estos métodos es la determinación de su efectiva relevancia para la declaración de los hechos que son objeto de prueba y decisión en el juicio. En otras palabras, se trata de establecer si, cuando y en qué condiciones, las neurociencias proporcionan conocimientos e informaciones utilizables como prueba en juicio, es decir, como instrumentos para establecer la verdad o falsedad (p. 15). 
En todo momento hace referencia a la pertinencia de la prueba, es decir, que la prueba tenga una relación causal con los hechos objetos del litigio y en caso contrario la prueba sería impertinente, por lo cual no podría ser admitida. En este trabajo se considera que esto no es un gran problema para la aplicación de las tecnologías neurocientificas; nuevamente se hará alusión al caso expuesto en el aparte anterior: el hombre de cuarenta años que a causa de una enfermedad -tumor cerebral- desarrolló un creciente interés en la pornografía infantil llevándolo a acosar a sus alumnos, efectivamente la resonancia magnética funcional por imágenes -técnica de la neurocienciafue la prueba determinante en este proceso, la cual corroboró en primera instancia que este sujeto tenía un tumor en su cerebro y en segundo lugar que la presencia de este era la causa de sus comportamientos pedófilos, así que ciertamente era una prueba que versaba sobre los hechos que se estaban debatiendo en el proceso. Con esto quedaría solucionado el asunto de la pertinencia de las pruebas que aportan las herramientas de las neurociencias en el proceso judicial. De igual forma, la admisión de la prueba científica para la plena demostración del estado de demencia.

Ahora bien, se ha señalado un problema de conducencia. Taruffo (2013) hace alusión al siguiente ejemplo:

En un proceso civil sucede con frecuencia que se debe determinar si un sujeto era capaz de entender y querer en un momento determinado (por ejemplo, cuando redactó un testamento o ha formalizado otro acto para el que se requería tal capacidad) (...) a lo que a reglón seguido explica es muy dudoso que las neurociencias puedan proporcionar resultados útiles para la solución de este problema (...) La primera de estas razones estriba en que en el cerebro no existe un área de la capacidad cuyo funcionamiento pueda verificarse para establecer si es normal, o se identifican anomalías de entidad suficiente como para concluir 
que el sujeto es incapaz. Otra razón es que los test neurocientíficos describen la situación del sujeto en el momento en que se llevan a cabo dichos test, pero no proporcionan ninguna prueba del pasado (p. 17).

En pocas palabras, el doctrinante se refiere al problema de las neurociencias para determinar si una lesión en el cerebro incide sobre la voluntad del sujeto, pero esto solo es un caso, lo cual no implica que todas las herramientas pertenecientes a esta ciencia conlleven a pruebas inconducentes, o que no se pueda reglamentar su utilización en la medida de su práctica y viabilidad científica. Siguiendo con el ejemplo del hombre que tenía el tumor cerebral, es evidente que la prueba de resonancia magnética por imágenes fue la más idónea y por tanto totalmente conducente.

Continuando este examen de admisibilidad de la prueba, se entiende que no se presenta ningún problema respecto la utilidad por lo cual no será estudiado.

Por otro lado, en cuanto al requisito de la licitud de la prueba se podría decir que presenta una dificultad; algunos estudiosos de la materia hablan de la obtención de esta "por vías antiéticas". Ello tiene razón, toda vez que la prueba ilícita se prohíbe dentro del proceso por ser obtenida infringiendo normas o principios establecidos en la Constitución y demás leyes, con el propósito de proteger las libertades públicas y los derechos de la personalidad y de su manifestación como derecho a la intimidad (Méndez, 2013). Los neurocientificos en la búsqueda de la resolución de problemas aún sin resolver a través de estas técnicas, podrían estar violando la intimidad propia del ser humano a un grado más elevado, y a su vez el sometimiento de una persona a estas técnicas por la averiguación de la verdad dentro de un proceso judicial podría ser análogo a los métodos utilizados en la antigüedad para la obtención de pruebas, que puede llegar a ser para aquellos sujetos un maltrato físico o psicológico. 
Este ámbito de la prueba neurocientífica no será agotado en esta ocasión, porque en definitiva se trata de analizar a profundidad otros temas como por ejemplo el plano de lo ético, asuntos que en este momento son de menor importancia para esta investigación. Así, como definir, medir el dolor, el daño moral de la mujer madre y del padre que se sometieron a tratamientos médicos para no concebir y resultaron procreando nuevamente, caso donde el tema ético es latente, no sólo por el sometimiento de los progenitores a la prueba neurocientífica sino también por el concepto de realidad y certeza de daño al concebir una nueva y humana vida.

Así las cosas, a grandes rasgos, quedaría depurada la prueba obtenida mediante las herramientas neurocientíficas para su admisibilidad en el proceso judicial.

El análisis anterior se hizo con la finalidad de establecer una correlación entre la prueba neurocientífica y la prueba del dolor, para no dejara dudas en cuanto a la admisibilidad de este tipo de pruebas y no ser refutado por aquellas bases que a continuación se expondrán y como eje central de este trabajo.

Los estudios de la neurociencia se extienden al plano del dolor, porque no hay duda en que este es percibido por el sistema nervioso, la información es recibida inicialmente por los nervios y llevada al cerebro -su ámbito de estudio-de los cuales se podrían establecer con certeza la existencia del dolor y su nivel de percepción, al siempre surgir dudas frente a la simple declaración de una persona o por la valoración según las máximas de la experiencia de indicios externos. En todo momento, este escrito se refiere al dolor padecido por un sujeto a consecuencia de una causa física o psíquica y a la evaluación de la intensidad del dolor.

El dolor es un hecho subjetivo, depende de quien lo sufre. Según la Asociación Internacional del Dolor (IASP, 2011) se "ha definido esta entidad como una experiencia sensorial subjetiva y emocional desagradable asociada con una lesión presente o 
potencial". Lo que implica concluir que el dolor es una realidad subjetiva que varía de una persona a otra (Puntillo, et al, 2001). Es decir, toca diversas esferas: sensorial, emocional, cognitiva, psicológica y de comportamiento o conductual. Lo cual conlleva a que lo indemnizable en un proceso judicial es la percepción del dolor. Por ello dentro de estos procesos se pueden dar comportamientos difíciles de contrarrestar con pruebas; como lo es mentir sobre la existencia del dolor o agravar la intensidad del mismo, todo ello con el fin de obtener una indemnización o aumentar la misma.

Es preciso anotar que el dolor puede ser físico o psíquico. Picó (2013) explica esta distinción con claridad:

El dolor físico es el que se produce por la alteración de cualquier zona del cuerpo humano (así, por ejemplo, el que surge por la amputación de un dedo de la mano, o el derivado de un esguince cervical producido en un accidente de tráfico) y el dolor psíquico es el que sin incidir en el aspecto externo del humano afecta al estado de ánimo produciendo dolor (así, por ejemplo, el causado por la muerte de un ser querido) (p. 84).

Aclarados estos conceptos básicos hay que decir que la prueba del dolor presenta ciertas dificultades técnicas y semánticas que harán mucho más compleja esta investigación debido a que ha habido una tendencia en la cultura jurídica en confundir los términos daño y dolor. Cuando el daño, este tipo de daño inmaterial, como detrimento, menoscabo, se encuentra condicionado necesariamente al dolor que se siente o que se continuará sufriendo para que, como daño, objeto jurídico indemnizable, pueda ser real, cierto, posible, determinado y medible monetariamente, lo que refuerza la idea sobre la existencia de una prueba del dolor considerando que sin dolor no hay daño. En otras palabras, la prueba del dolor es el modo demostrativo de este particular daño: Cargar antijurídicamente con un dolor. 
En consecuencia, se ha de pagar la indemnización de acuerdo con la intensidad del dolor y, midiendo ese dolor, se cuantifica para cubrir o solucionar, pagar jurídicamente el daño causado.

\section{Diferencias entre daño y dolor}

Al abordar el estudio de la responsabilidad desde la visión del resarcimiento del "daño" se plantea los distintos procesos que se desarrollan dentro del marco económico y social en relación con revalorización del concepto de persona y de su representación dentro de los sistemas jurídicos, por lo que "la persona ha dejado de ser entonces un simple titular de derechos subjetivos patrimoniales para asumir un papel importante en la defensa de los atributos de su personalidad, es decir:

Los nuevos valores y reconocimientos gravitan en torno al valor de la persona (no entendida como mercancía), se contrapone la gran complejidad que conllevan tanto la valoración de esos otros intereses que emergen como dignos de tutela como la evaluación y reparación que debe entrar a efectuar el juez (Sandoval, 2013, pp. 239-240).

Con ello se impone un nuevo esquema de responsabilidad, que comienza a imponer a los jueces un nuevo pensamiento de enfoque de transformación del derecho hacia una visión en la cual los intereses se centran en las victimas producto de hechos dañosos.

Ante todo, debe distinguirse entre daño y dolor pues a pesar de ir unidos -razón por la que tiende a confundirse- son dos conceptos totalmente distintos, al punto que, reiteramos, sin dolor pasado, presente y/o futuro, no hay daño. El dolor causa el daño. Es pertinente anotar que se ha producido una confusión frente al uso de ambos términos tanto en la ley, la jurisprudencia y la doctrina, aspectos que serán estudiados a continuación. 
El problema está en el Código Civil en su artículo 2341 al establecer que "el que ha cometido un delito o culpa, que ha inferido daño a otro, es obligado a la indemnización”. De allí que el vínculo de causalidad sea un elemento esencial de la responsabilidad civil, en esta doctrina de la "Culpa Probada". Antolissei citado en Suescún (2013) explica:

La razón por la cual se requiere que entre la conducta y el evento exista un nexo de causalidad, consiste en que, solamente cuando exista, este evento puede ser referido o relacionado con el agente o imputado a este y cargado a él como fundamento de su responsabilidad, de suerte que cuando preventivamente se sabe que al demandado no se le puede imputar el evento dañino físicamente, porque la causa de este resiste en extraños, sin cuyo obrar no se habría producido, no se le puede cargar a él la responsabilidad, cualquiera que sea el grado de culpa en que él haya incurrido (p. 140).

De lo que se infiere que la importancia del vínculo causal está en que éste permite relacionarlo con el agente o imputado, definiendo su responsabilidad y en consecuencia pague los perjuicios económicos derivados del daño. En otras palabras se refiere en primera instancia a una relación causa-efecto entre culpa y daño para que pueda ocurrir la indemnización; por tanto no hay cabida al dolor a primera y superficial vista en esta teoría que presenta el código civil; sin embargo, nótese como la disposición jurídica no identifica la clase de daño que debe repararse, por lo que, en sana interpretación, no excluye el daño inmaterial, moral, que proviene del dolor. Lo que podría afirmarse es que la norma efectivamente consagra la relación entre culpa y daño, sistema culpabilista clásico que refleja el Código Civil acorde con la época de su expedición, que se conserva sin ser el único, y es, en ese postulado, lo que permite que exista una indemnización para solventar el daño, pero en esencia ese 
daño ocasionado por el dolor que está asumiendo el sujeto afectado. Por tanto, el daño es una consecuencia exteriorizada del dolor, percepción dolorosa que, en su extensión o delimitación neurocientíficas, serviría para liquidar objetivamente el daño.

Ahora bien, en concordancia con la anotación del profesor Suescún (2013): "si el daño no puede ser atribuido al demandado, este debe ser necesariamente exonerado, pues cada uno debe ser juzgado de acuerdo a sus actos y omisiones" (p. 140). Notoriamente, este comentario hace relación a la imputabilidad del daño y no a la cuantificación del mismo, y sin darle este alcance conllevaría un problema semántico. Sí no hay daño y más aún si no se puede atribuir éste al agente que lo ocasionó, habrá lugar a la exoneración de responsabilidad lo que implica el no pago de los perjuicios, por tanto, no se podría hablar de atribución del dolor. En consecuencia, no podría sin poderse indemnizarse el daño producido por el dolor, cuando a lo que se hace referencia en el aparte doctrinario comentado es al eximente de responsabilidad por no existir un imputable que responda.

Otro problema, es que tanto la jurisprudencia como la doctrina hablan de la existencia de una relación causal directa y necesaria entre el hecho culposo y el daño. Alessandri (citado por Suescún, 2013) lo ilustra de la siguiente manera "no importa que el daño tenga varias causas o se produzca de inmediato o después, lo esencial es que la culpa haya sido la causa directa y necesaria, es decir, que sin ésta el daño no se hubiera generado" (p. 141), generándose interpretaciones erradas sobre la presencia o no del daño por la comisión o no de una culpa. El dolor tasado y su consecuente daño así medible se producen por culpa o sin esa conducta, el comportamiento de quien causa ese dolor y ese daño son útiles para imputar el daño no para la generación del mismo. El dolor y el daño sin causante imputable no será reparado por otro, porque, no obstante su presentación, no hay sujeto de derecho a quien endilgarlo para 
hacerlo responder. Es un intrínseco dolor y personal daño que no trasciende a la esfera de la responsabilidad civil, económica, patrimonial.

Lo que se ha examinado hasta ahora demuestra que hay una cultura jurídica frente al termino "daño" y en general en la teoría de la responsabilidad, en relación con lo cual este trabajo en su objetivo pretende ofrecer métodos científicos para demostrar y medir el típico daño inmaterial con la precisión de la intensidad del dolor, que, si bien difícilmente podría cambiarse, pero queremos hacer comprender que cuando se experimentan este tipo de situaciones que generan responsabilidad, secuencialmente ocurre un hecho dañoso porque produce dolor y seguidamente, se origina un daño, algo que sucede en cuestión de segundos y es lo que en ultimas determina las razones por las cuales se genera una indemnización.

Por otro lado, también se expondrá que en últimas las teorías de responsabilidad hablan de daño para atribuir fácilmente a quien lo ocasionó, es para imputar la responsabilidad, pero esto no implica que el daño sea el motor de estas teorías; sino el dolor, o en ánimo conciliatorio, el daño, en este caso inmaterial, daño moral que no puede tener presentación alguna sin el precedente dolor como auténtico legitimador o fuente del vínculo jurídico para demandar la respectiva indemnización. Porque, para el daño moral o inmaterial, sí ocurre un hecho y este no generó ningún tipo de dolor no podría generar daño, sin lugar a la indemnización.

Por consiguiente, el vínculo de causalidad entre daño y culpa constituye un elemento de imputabilidad para la subsiguiente responsabilidad civil y no un determinante para precisar el dolor con el consecuente daño y pagar, en el monto que se obtenga de ese cálculo, una indemnización. Sí, efectivamente hay responsabilidad, habrá lugar a la indemnización pero lo que se indemniza es el daño que produjo el dolor que debe ser el objeto de concreción probatoria -científica. Así, el dolor, su daño, la 
culpa, o la objetiva relación entre los sujetos intervinientes, el vínculo de causalidad, entre otros, son los elementos que permiten determinar la responsabilidad civil de reparación. Pretensiosamente se afirma en este escrito, que son los elementos que reunidos conducen la teoría responsabilidad patrimonial, iniciando en la obtención de la prueba del dolor científicamente medido para que prospere la demanda indemnizatoria.

En cuanto al hecho de que el dolor es subjetivo y por tanto es difícil probarlo, es algo que hay que desmitificar. Cuantificado el dolor ya demostrado científicamente, emerge el daño consecuente y se posibilita la prueba de los demás elementos de la responsabilidad civil. Pensemos en la típica situación donde una persona va cruzado la calle y el semáforo se encuentra en verde a su favor y otro sujeto va conduciendo a alta velocidad y no se percata de que el semáforo esta en rojo y mucho menos que aquel sujeto va cruzando. Efectivamente, el impacto del auto con el cuerpo de la persona ocasiona dolor, esta es una situación totalmente anormal, desagradable e imprevista en el cuerpo del sujeto producto del hecho que le ocasiona el dolor y el daño, por eso se le denomina hecho dañoso. En consecuencia, se tiene el hecho dañoso, que también podríamos resaltarlo como hecho creador de dolor, hecho doloroso, (el impacto del auto con el cuerpo del sujeto) que hace prorrumpir el dolor, manifestación negativa del sistema nervioso que advierte que el cuerpo se encuentra en una condición de anormalidad y el daño, que es la exteriorización de ese dolor, pudiendo ser física o interna o ambas.

Si el daño es una exteriorización del dolor, basta con probar éste como resultado de la medición del dolor. Valga la redundancia, para probar existencia de que se ocasionó dolor sin el cual no es posible el daño. Entonces, de forma general, se podrían arrojar tres presupuestos: en primer lugar, que todo este tiempo implícitamente se ha probado el dolor, por otro lado el problema de la prueba del dolor ha quedado resuelto parcial- 
mente en cuanto a la prueba de su existencia y finalmente que en esencia lo que se está indemnizando es el dolor y, por tanto, se debe hablar de una medición y cuantificación del dolor, con lo cual quedaría determinado el daño y su valor económico a reparar como perjuicio.

Igualmente, hay una confusión entre el dolor y daño moral, a lo cual explica el profesor Picó (2013) que son dos realidades distintas: "así, es perfectamente posible que exista daño y dolor a la vez, pero que uno perdure en el tiempo más que el otro; que haya daño sin dolor; y dolor sin daño moral indemnizable" (p. 85).

A reglón seguido expone tres escenarios, a modo de ejemplo, que se podrían presentar frente a esta confusión, que se estima conveniente plasmar para una mayor claridad en el tema.

Mediante una mala praxis médica se ocasiona una cicatriz, si no se elimina la cicatriz podría durar toda la vida, por lo que podrá existir daño moral sin dolor. Este es el caso más común; donde existe daño moral y dolor pero el daño moral perdura más tiempo que el dolor. Sin embargo, nótese que no habrá dolor físico, así debemos entender la tesis, la cicatriz ya no causa ese dolor, pero avergüenza subjetivamente a quien debe taparse o trata de esconderla para no mostrarla, es esto un dolor manifestado como pena que le causa esa cicatriz.

Un sujeto que sufre tetraplejia, existe un daño indemnizable, entre los cuales está el moral y puede haber ausencia de dolor debido a la falta de sensibilidad en las extremidades. Este es un caso excepcional, donde existe daño moral sin dolor. De igual forma, para este caso en que no sería posible medir el dolor que sintió cuando se produjo el accidente, la jurisprudencia ha venido reconociendo que la pérdida de condiciones normales de vida, perjuicios fisiológicos o el de alteración de salud, daño todos inmateriales, son manifestaciones dolorosas que causan daño y deben ser indemnizadas. 
Finalmente, cuando a un sikh se le corta el cabello porque entra en un proceso penitenciario, lo cual le causa dolor pero ausencia de daño moral. También es un caso excepcional donde se produce dolor sin daño moral indemnizable ${ }^{3}$.

Daño y dolor han tendido a confundirse incluso desde la misma jurisprudencia, la palabra más aproximada de dolor es perjuicio, sin embargo la misma Corte confunde perjuicio con daño. En 1977 plasmó la Corte Suprema de justicia "para que un perjuicio sea objeto de reparación económica tiene que ser directo y cierto: lo primero porque solo corresponde indemnizar el daño que se presente como consecuencia de la culpa" esto conlleva a que se hagan apreciaciones erróneas y se maximicen las desconciertos frente al tema y desde ya acoja la útil y practica distinción entre daño y perjuicio: Daño $=$ Detrimento --- Perjuicio $=$ Medición monetaria del detrimento. Para el objeto de este trabajo investigativo, proponemos: DAÑO INMATERIAL --- DOLOR = Quebranto CIENTÍFICAMENTE MEDIDO como productor de DAÑO --- PERJUICIO: Medición monetaria de ese quebranto, para cuantificar e indemnizar el DAÑO CXAUSADO POR EL QUEBRANTO.

\section{Propósito de la reparación}

$\mathrm{Al}$ principio de este texto se dejaron en tentativa unos interrogantes: ¿Sería más apropiado indemnizar y cuantificar el dolor? Pero si el dolor es subjetivo ¿Cómo cuantificarlo? A los cuales se sumaran ¿Cuál es el propósito de la reparación? Se empezará por responder este último.

Cuando un sujeto ocasiona un dolor y en consecuencia un daño a otro sin que exista un fundamento jurídico para que ese sujeto deba soportar de manera exclusiva dicho detrimento, se produce en el ordenamiento jurídico una reacción para el autor de aquella acción o por quien por él deba responder, repare o compense. La

3 El daño moral no indemnizable no es por la causa o no del dolor, es porque está sancionado y es un dolor o daño que debe soportar en la legítima coacción que le impone la autoridad. 
doctrina concuerda en decir que esto se hace con el propósito de que el afectado quede en una situación similar a la que tendría si el hecho dañoso no se hubiera presentado.

En resumen, el propósito de la reparación es la reposición de las cosas en el estado anterior, es decir, que los efectos del hecho dañoso desaparezcan, esto podría ser totalmente cierto si en todas las situaciones se pudieran revertir los efectos como lo es el caso de un auto que impacta a otro causando exclusivamente daños patrimoniales, con una reparación al mismo quedaría subsanado; sin embargo, pensemos en el caso de un sujeto que causa accidentalmente la muerte de otro, los efectos que produce esta muerte, más allá de los daños materiales, es un dolor psíquico a los familiares de aquel sujeto, cuyos efectos no se pueden borrar. Sin embargo, el proceso reparatorio civil, patrimonial y económico, es lo que distingue este sistema, esta filosofía, que desarrolla históricamente el concepto de reparar incluso el dolor, como forma de solventar el daño que se causa por ese menoscabo físico o síquico o simplemente inmaterial. Es el derecho civil el que ha hecho posible medir en valores monetarios derechos inmateriales vulnerados por otros sujetos de derecho que no pueden ser exonerados del pago indemnizatorio, y sin desconocer los efectos punitivos paralelos, como lo señala el artículo 2341 del C.C., "(...) sin perjuicio de la pena principal por el delito o culpa cometidos." Por esa y otras razones, este trabajo se acoge a la tesis de que el propósito de la reparación es la de reparar el daño, sin desconocer, que a élla se puede sumar un propósito sancionatorio por transgredir el ordenamiento jurídico, en razón de la injusticia del dolor causado al sujeto que él no estaría dispuesto a soportar: El dicho coloquial puede ilustrar la idea indemnizatoria sobre la pesadumbre y la aflicción: "Dolor con dinero se siente menos." Es así como el ordenamiento reacciona imponiendo sanciones adicionales que igual pueden consistir en otros pagos monetarios como cláusulas penales, o configuraciones simbólicas en peticiones públicas de perdón o construyendo 
monumentos de recordación. El dolor y el daño se dieron, no podemos regresar al tiempo ya consumado, para que no se cometa la violación de una obligación de no hacer daño habiendo causado dolor irreversible que no desaparecerá, "nadie está obligado a lo imposible", pero el perjuicio, mediante solución económica por su medición aceptada en derecho, quedará compensado.

Es aquí donde juega un papel importante las técnicas de las neurociencias, para la determinación de la existencia y la intensidad del dolor, por lo que la ciencia facilita la prueba del dolor. "recientes avances en neurociencia han permitido, mediante imágenes computarizadas, detectar la región del cerebro que se activa cuando se aplican estímulos dolorosos (la matriz del dolor), por lo que con ellas es posible probar la existencia del dolor" (Picó, 2013, p. 90). Con ello queda resuelto uno de los problemas que planteamos al principio de este trabajo, dado que con la posible medición científica del dolor, nos acercamos a su indemnización integral en esta idea jurídica y económica.

\section{Cuantificación del dolor.}

García (2007) nos plantea que:

Para resarcir el daño, el Estado tasa el dolor. El interés de darle un precio al dolor radica en: primero, resarcir el daño; segundo, sancionar y expiar al Estado por la falta que ha cometido; tercero, mitigar o proporcionar alivio y satisfacción por el dolor causado cuando no puede ser resarcido. De modo que la cuantificación de ese dolor, para Colombia, ha quedado en manos de los jueces, quienes deben observar las circunstancias específicas de cada individuo y recurrir, además, a las herramientas que la experiencia humana les pueda brindar (p. 85).

Sin embargo, se reconoce que no existe un 'Dolorímetro' que permita medir el dolor en dinero y otros bienes intangibles, sobre esto, la neurociencia ha desarrollado diversos métodos que 
permiten medirlo; a pesar de que la valoración del dolor es una tarea muy difícil en razón de su componente subjetivo.

Sólo el propio paciente conoce su dolor y cuánto le duele, por ello, toda valoración del mismo debe atender necesariamente el informe del enfermo. Si todas las mediciones incluyen un error de diverso grado, sobre todo, la medición de un fenómeno subjetivo por su arbitrariedad, estarán cargadas de potenciales problemas. Así, la medición del dolor es una de las tareas más difíciles con las que se encuentra tanto el clínico como el investigador (Serrano, et al., 2002, p. 94).

Por ello para su valoración se deben utilizar unos parámetros y componentes de tipo psíquico, físico, espiritual, entre otros; lo que ha desembocado en múltiples procedimientos para medir el dolor, así como técnicas de evaluación psicológica.

Es de aclarar que la idea de este acápite del texto no es profundizar en las técnicas desarrolladas para la medición del dolor; sino mostrar que estas existen y que es posible cuantificar el dolor. Igualmente se deja claro que "no es posible extrapolar el dolor producido en el laboratorio, con el dolor clínico causado por un proceso patológico. El ingrediente que falta es el estado psicológico del paciente, asociado con la enfermedad o la amenaza de muerte" (Serrano, et al., 2002, p. 95). Lo que incrementa la dificultad de su estudio de forma experimental. Así las cosas se mencionaran y explicaran someramente algunos de estos métodos.

Existe una valoración experimental del dolor subjetiva y otra objetiva. La primera comprende métodos unidimensionales, duales, y multidimensionales, ejemplos de estos es la escala analógica visual (EVA). La segunda comprende métodos como el registro directo de los nervios periféricos, registros electromiográficos, imágenes cerebrales: PET, entre otros. Estos últimos métodos están asociados al desarrollo de las neurociencias y los primeros a la medicina clínica y psicológica. 
De acuerdo a lo anterior, para la medición del dolor y en últimas para su cuantificación, se propone la combinación del uso de ambos métodos -subjetivo y objetivo-. En un primer grado se arrojará una estimación subjetiva del dolor con los ensayos de los métodos subjetivos, en los cuales se calificará la participación de otros elementos implicados en la experiencia dolorosa y en un segundo grado con la valoración objetiva del dolor se confirma la validez de la estimación de la subjetiva. En resumen no existe una única prueba del dolor; sino que es la integración de una variedad de técnicas de la neurociencia y otras ciencias, como podría ser la piscología que se refiere a las técnicas de la visual analogue scale (VAS).

Haciendo alusión a la breve introducción que se realizó en esta parte del trabajo, el Derecho Procesal debe ser interdisciplinario así que en la búsqueda de la verdad dentro del proceso judicial, como objeto principal del mismo, se deberían utilizar diferentes herramientas para probar un mismo hecho siempre y cuando una prueba no satisfaga lo suficiente y en caso de que no se encuentren más al respecto deberían quedar como indicios. Tal es el caso de las herramientas de las neurociencias. Al respecto, Picó (2013) expone una formula probática del dolor la cual requiere de la combinación de varias técnicas, como lo son la prueba documental que consiste en las historias clínicas de las personas afectadas por el dolor, así como la prueba pericial que hace alusión al uso de las técnicas neurocientíficas, entre otras. Sin lugar a dudas si esta integración se implementa en los procesos judiciales pondría fin a los vacíos legales que existen frente a la prueba del dolor.

\section{Vacío legal de la prueba del dolor}

A pesar de que ya ha quedado resuelto la forma como probar la existencia y la intensidad del dolor, queda por resolver el último interrogante que se ha planteado en esta investigación y es si realmente existe un vacío legal frente a la prueba del dolor, que 
se centra en aquellos asuntos que pese a la aspiración del legislador de prever todas las hipótesis posibles, siempre quedan fuera de ellas casos no imaginados (Galiano y González, 2012). Evidentemente, habiendo o no la utilización del término "prueba del dolor", siempre ha existido en el ordenamiento jurídico la figura de la reparación por el daño causado que puede manifestarse en una indemnización, por ejemplo; que sería el mismo fin que se consiguiera probando el dolor dentro de un proceso judicial; sin embargo lo que no se ha examinado a fondo es que esa reparación intrínsecamente también corresponde al dolor padecido, diríamos que sería una reacción ante el hecho dañoso que ocasionó dolor y daño, porque necesariamente, como viene explicado tenemos que imputar el dolor para encontrar al responsable de su causación en aras de obligarlo a la indemnización.

En el ordenamiento jurídico existen tasas jurisprudenciales de cuantificación del daño, incluso del inmaterial, las cuales son fijadas al arbitrio del administrador de justicia. No obstante, no existe nada respecto al dolor y es que como ya se ha explicado el dolor es una percepción, por tanto la intensidad que una persona podría percibir frente a un hecho que le cause dolor no es la misma que podría percibir otra. Pensemos en el escenario donde un sujeto muere por un impacto con una moto por culpa imputable al conductor, este sujeto tiene padres, hermanos, hijos y cónyuge. Los grados de intensidad de percepción del dolor de estas personas serán diferentes; sin embargo, la ley o la jurisprudencia no habla de una indemnización que dependa de esa intensidad, no hay una jurídicamente aceptada medición del dolor para su cuantificación económica como perjuicio. En consecuencia, si existe el vacío legal que se trata de suplir mediante la simple presunción humana.

Ahora bien, la cuestión aquí es preguntarse porque el legislador hace caso omiso a esto, si ya se ha demostrado la posibilidad probatoria científica y objetiva del dolor. El problema, como explica Picó (2013) es para "evitar las desigualdades que se podrían 
producir al otorgar judicialmente indemnizaciones muy dispares ante daños similares" (p. 87). Siguiendo el ejemplo anterior, para el ordenamiento jurídico sería muy injusto conceder una indemnización mayor a la viuda porque en los estudios de experticia y demás pruebas se demostró que percibió más dolor que el padre del muerto. Pero esto a su vez plantea una situación injusta ya que el dolor es una percepción por tanto su reparación debe ir conforme al logro de esta realidad y certeza como elementos ineludibles en el objeto de obligaciones en derecho.

Otra cuestión y a la que acudirían otros doctrinantes, es afirmar la inexistencia de vacíos legales por considerar que un ordenamiento jurídico tiene principios que lo tornan cerrado y en esa medida le permite llenar los vacíos, resolviendo todas las situaciones no expresamente normadas que en dicho ordenamiento pueden producirse (Kelsen, 1960). No obstante, lo cierto es que al sostener que el juez puede resolver todos los casos que se le presenten con la aplicación del derecho existente, sin necesidad de modificarlo (Basterra, 2013), se concreta en aceverar que aunque se resuelve el caso concreto, sigue existiendo el vacío legal.

\section{Conclusiones}

De acuerdo al análisis planteado, el daño es una exteriorización del dolor; por lo cual y en esencia, lo que se está indemnizando es el dolor que produce daño, por tanto se debe hablar de una cuantificación del dolor y no del daño, para la consecuente y real medición del daño y pago monetario del perjuicio. Ahora bien, este último, el daño, en concordancia con la normatividad y la jurisprudencia, es el tasado para la respectiva indemnización, lo que constituye un error. Así las cosas, ha quedado demostrada la existencia de un vacío legal, esto es, la ausencia de una prueba del dolor dentro del ordenamiento jurídico, teniendo en cuenta la naturaleza del dolor que se ha descrito en el presente trabajo, vacíos que no son atribuibles a los cambios sociales ni imputables al legislador. 
El dolor represente un problema, que es la graduación del mismo, por lo que se ha preferido optar por tazar el daño, configurándose como la forma correcta de indemnizar el dolor, pues, dentro de las herramientas que tiene el Derecho no existe otro proceder, y de no ser así se incurriría en el desconocimiento de un pago por los perjuicios ocasionados.

No obstante ello, el derecho no ha examinado la importancia del uso de nuevas prácticas descubiertas por la ciencia. Así, el trabajo expuesto, permite concluir que las neurociencias ha desarrollado diversos métodos que permiten medir la intensidad y variables del dolor, que podría acercarnos a la denominada y hoy ausente prueba del dolor; Sin embargo, este no debe ser el único método utilizado, porque el Derecho debe ser interdisciplinario, por lo cual, en la prueba del dolor se requiere de una mixtura de varias técnicas, como lo son los métodos de valoración subjetivo y objetivo, lo que en términos generales, solucionaría el vacío legal explicado.

Ahora bien, solventado el problema que dio inicio al presente trabajo, paralelamente surge otro de igual importancia. A pesar de hallarse los métodos mencionados en el párrafo precedente y su posibilidad probatoria que permiten solucionar la desigual que se podría presentar de la no cuantificación del dolor, toda vez, que el dolor es una percepción subjetiva por tanto su reparación debe estar de conformidad con la realidad, posibilidad y certeza que son ineludibles elementos del objeto obligacional en derecho. Así mismo, se podría considerar desigual el hecho de que se generen indemnizaciones dispares a hechos similares, lo que sería contrario a derecho si de temas constitucionales se refiere. Que de acuerdo, al desarrollo de este texto investigativo, lo aceptable sería escoger la primera opción, es decir, la de permitir el uso de una prueba del dolor en los procesos judiciales, que permitan al juez fallar de conformidad con la realidad y no bajo supuestos o ficciones. 
De allí la complejidad de los diferentes conceptos aportados en este trabajo reflexivo, demostrando la necesidad de una armonización entre las ciencias jurídicas y las ciencias naturales para la generación de nuevos conceptos en Derecho y con ello una reestructuración del mismo. De este modo se ha dejado expuesto que el Derecho, dada su naturaleza, no es estático y con el uso de otras disciplinas, como lo son las neurociencias, es viable un progreso más completo del Ordenamiento Jurídico. A partir de las apreciaciones desarrolladas en este trabajo se puede concluir, de una parte que los avances de las neurociencias conllevan a reevaluar conceptos tradicionales en el Derecho como lo es el daño y la posibilidad de probar el dolor; sin embargo, estos avances se deben valorar críticamente en su uso, puesto que aún existen dudas frente a su fiabilidad, por lo cual es imprescindible la aplicación de los criterios Daubert en la valoración de dictámenes periciales que se basen en técnicas de las neurociencias.

\section{REFERENCIAS}

Arteaga, S. (2018). ¿Cómo funciona el cerebro político? Guía de comunicación política para entender a los votantes y a la opinión pública. Revista Jurídica Mario Alario D’Filippo, 10(20). 187-212. (Online). Recuperado de https://revistas. unicartagena.edu.co/index.php/marioalariodfilippo/article/ view/2155/1755

Basterra, M. (2013). El problema de las lagunas en el Derecho. Revista Derecho \& Sociedad, 15(1). 280-291. (Online). Recuperado de http://revistas.pucp.edu.pe/index.php/ derechoysociedad/article/viewFile/17178/17466

BNA. (2003). Neurociencias. La ciencia del cerebro: una introducción para jóvenes estudiantes. Liverpool: BNA. (Online). Recuperado de https://es.slideshare.net/ alehlizarraga/neurociencias-15560160 / https://natureduca. com/salud-neurociencias-la-ciencia-del-cerebro-tacto-ydolor-01.php 
Cárdenas, R. (2017). Neurociencia y derecho: problemas y posibilidades para el quehacer jurídico. Bioethics UPdate 3(2). 82-106. http://dx.doi.org/10.1016/j.bioet.2016.12.001

Galiano, G. y González, D. (2012). La integración del derecho ante las lagunas de la ley. Revista Dikaion, 21(2). 431-458. (Online). Recuperado de http://www.scielo.org.co/pdf/dika/ v21n $2 / v 21 n 2 a 06 . p d f$

García, G. (2007). El precio del dolor: el dolor desde el derecho administrativo. Revista Jurídicas. Universidad de Caldas. 4(2). 81-94. (Online). Recuperado de http://juridicas.ucaldas. edu.co/downloads/Juridicas4-2_6.pdf

Kelsen, H. (1960). Teoría pura del derecho. Buenos Aires: Eudeba. IASP. (2011).

Llinás, R. (2003). El Cerebro y el mito del yo: el papel de las neuronas en el pensamiento y el comportamiento humanos. Bogotá, D.C.: Norma.

López, D. (2000). El Derecho de los Jueces. Bogotá, D.C.: Legis.

Luna, F. (2018). El mito del cientificismo en la valoración de la prueba científica. Jurídicas CUC, 14(1). 119-144. http:// dx.doi.org/10.17981/juridcuc.14.1.2018.6

Méndez, R. (2013). La valoración constitucional de la prueba ilícita e ilegal en la República Federal de Brasil. Justicia Juris, 9(2). 74-84. (Online). Recuperado de http://www. scielo.org.co/pdf/jusju/v9n2/v9n2a08.pdf

Mercado, F. (2011). Necesidad de reglamentar las donaciones recibidas por las unidades educativas del sistema fiscal (Tesis de pregrado). Universidad mayor de San Andrés, La Paz, Bolivia.

Molina, R. (2013). Neurociencia, Neurótica, Derecho y Proceso. En, M. Taruffo y J. Nieva (Dirs.), Neurociencia y proceso judicial (43-81). Madrid: Ediciones jurídicas y sociales.

Picó, J. (2013). La prueba del dolor. En, M. Taruffo y J. Nieva (Dirs.), Neurociencia y proceso judicial (83-96). Madrid: Ediciones jurídicas y sociales. 
Puntillo, K., White, C., Bonham, A., Perdue, S., Stanik-Hutt, J., Thompson, C. \& Rietman, L. (2001). Patients' perceptions and responses to procedural pain: results from Thunder Project II. American Journal of Critical Care, 10(4), 238251.

República de Colombia. Corte Constitucional. (14 de mayo de 2014). Sentencia C-283. MP: Jorge Iván Palacio Palacio.

República de Colombia. Corte Constitucional. (1 de abril de 2005). Sentencia T-309. MP: Jaime Córdoba Triviño.

Reyes, I., Hernández, J., Chumaceiro, A. y Cadrazco, C. (2016). Epilepsia un abordaje social: experiencia de sensibilización y concientización ciudadana. Orbis, 12(35). 58-76.

Rocha, C. (2013). Derecho y Neurociencias. Bogotá, D.C.: Academia Colombiana de Jurisprudencia.

Sandoval, D. (2013). Reparación integral y responsabilidad civil: el concepto de reparación integral y su vigencia en los daños extrapatrimoniales a la persona como garantía de los derechos de las víctimas. Revista de Derecho Privado, 25(1). pp. 235-271. Recuperado de http://www.scielo.org.co/ pdf/rdp/n25/n25a10.pdf

Serrano, M., Caballero, J., Cañas, A., García, P. y Serrano, C. (2002). Valoración del dolor. Revista de la Sociedad Española del dolor, 9(1), 94-108. (Online). Recuperado de http://revista.sedolor.es/pdf/2002_02_05.pdf

Suescún, J. (2013). Derecho Privado: estudios de Derecho civil y comercial contemporáneo. Bogotá, D.C.: Legis.

Taruffo, M. (2013). Proceso y Neurociencia: aspectos generales. En, M. Taruffo y J. Nieva (Dirs.), Neurociencia y proceso judicial (15-24). Madrid: Ediciones jurídicas y sociales. 
Fernado Luna Salas es Abogado de la Universidad de Cartagena (Colombia), Especialista en Derecho Procesal de la Universidad Libre (Colombia), Magister en Derecho de la Universidad de Cartagena. Profesor en el área de Derecho Procesal y Probatorio en la Universidad de Cartagena. Editor de la Revista Jurídica Mario Alario D' Filippo de la Facultad de Derecho y Ciencias Políticas de la Universidad de Cartagena. Director del Semillero de Investigación "Ciencia y Proceso" y coinvestigador del Semillero de Investigación "Neurociencia y Derecho", los cuales están vinculados al grupo de investigación "Filosofía del derecho, derecho internacional y problemas jurídicos contemporáneos" de la Facultad de Derecho de la Universidad de Cartagena. Director del Capítulo Regional Bolívar de la Asociación Colombiana de Derecho Procesal Constitucional (ACDPC).

Virgilio Escamilla Arrieta es Abogado de la Universidad de Cartagena (Colombia), Magister en Derecho Administrativo de la Universidad Libre (Colombia), Especialista en Derecho Público de la Universidad de Cartagena-Universidad Externado (Colombia), Especialista en Administración Pública de laUniversidad de Cartagena-Escuela Superior de Administración Pública (Colombia), Conciliador y Arbitro (Centro de Conciliación y Arbitraje-Cámara de Comercio de Cartagena), Docente Universitario (Obligaciones y Contratos - Universidad Libre - Universidad de Cartagena).

Adriana Corena Simancas es Abogada egresada de la Facultad de Derecho de la Universidad de Cartagena (Colombia), Investigadora del Semillero de Investigación "Ciencia y Proceso" de la misma universidad. 